\title{
INTERCERAM Reinvents Itself
}

Did you recognise INTERCERAM at first glance? I hope so. Just like all other products, it is also necessary from time to time to take a closer look at informative and specialist media to make sure of their presence and effectiveness. Do they still look attractive? Is their subject matter up-to-date and clearly aimed at their target groups? Does the magazine express a convincing image of high quality?

Following the acquisition of INTERCERAM and Keramische Zeitschrift by Springer Fachmedien $\mathrm{GmbH}$ earlier this year, we addressed these and other questions and decided to undertake a relaunch of both of these specialist journals.

This year's ceramitec is without doubt an excellent opportunity to present our "new" journals to a specialist public. But while the media themselves may have a new look, the editorial responsibilities remain the same. And I will continue in my role as editor in chief.

It goes without saying that these long-standing ceramics journals will take a prominent place in the
Springer media landscape. We will publish the latest news from the world of ceramics through a variety of digital channels, helping to raise awareness of the industry. As a reader or advertising customer, you will still recognise those features that have made these journals so successful, but in addition you will now be able to benefit from the opportunities offered by a major international media company.

Springer Fachmedien is Europe's second largest publisher of high-quality magazines and specialist books and, at www.springerprofessional.de, has one of the biggest digital libraries with continuously updated technical and industry information, which is also distributed to specific target groups through a regular newsletter.

I cordially invite you to visit us at ceramitec in Munich to find out more about the Springer media world and to have an opportunity to test your dexterity. Curious? Well let us surprise you! You can find us in Hall A5/ Stand 219. We look forward to seeing you there.

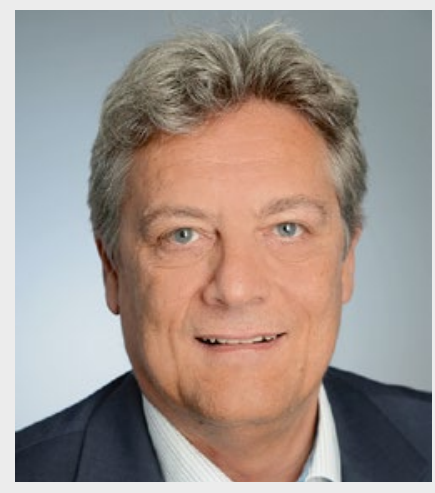

Dr. Hubert Pelc Editor in Chief, hubert.pelc@springer.com 